\title{
Bem-estar e o mal-estar docente: sentimentos e emoções de professores que atuam na Educação Infantil e Ensino Fundamental em tempos de pandemia
}

\author{
Well-being and teacher malaise: feelings and emotions of teachers working in \\ Kindergarten and Elementary School in times of pandemic
}

\begin{abstract}
Bienestar y malestar docente: sentimientos y emociones de los docentes que trabajan en el jardín de infancia y la escuela primaria en tiempos de pandemia
\end{abstract}

\author{
Eliane Terezinha Tulio Ferronato ${ }^{1}$ \\ Helen Thais dos Santos ${ }^{2}$
}

\begin{abstract}
Resumo: O presente estudo visa a analisar a percepção e os sentimentos de bem-estar e malestar dos professores, sobre o ensino remoto em tempos de pandemia. autores, como Esteve (1999), Nóvoa (2009), Santos (2020), Saviani e Galvão (2021), Brooks (2021) e outros, auxiliaram no suporte teórico para entendermos o complexo trabalho da docência. A coleta de dados se deu por meio de questionário on-line pelo google forms para todos os professores da Educação Infantil e Ensino Fundamental do município de Maracaju - MS. Sem sombra de dúvida o professor foi uma das profissões com mais fatores de mal-estar, porém também foi a profissão que mais se reinventou durante a pandemia, superando várias dificuldades, entre
\end{abstract}

\footnotetext{
${ }^{1}$ Possui graduação em Pedagogia Pré Escola e Séries Iniciais pela Universidade Estadual de Mato Grosso do Sul (2003). Mestrado em politicas públicas pelo Programa de Pós-Graduação - Universidade Católica Dom Bosco (2009). Doutorado em educação na Linha de pesquisa "Práticas Pedagógicas e suas Relações com a Formação Docente" pelo Programa de Pós-Graduação - Universidade Católica Dom Bosco. Atualmente é professora adjunta da Universidade Estadual de Mato Grosso do Sul; pesquisadora/integrante do Grupo de Estudos e Pesquisa Formação, Trabalho e Bem-estar Docente (GEBem/CNPq) da Universidade Católica Dom Bosco e vice lider do grupo de pesquisa GRUPO DE ESTUDOS E PESQUISA EM PRÁTICAS PEDAGÓGICAS ESCOLARES, TRABALHO DOCENTE E FORMAÇAO DE PROFESSORES PARA INFÂNCIAS (GEPINFÂNCIAS/CNPq). Tem experiência na área de Educação, com ênfase em politicas públicas e formação de professores, atuando principalmente nos seguintes temas: alfabetização e letramento, educação infantil, professor iniciante e bem-estar/mal- estar docente. E-mail: nany@ uems.br. ORCID:https://orcid.org/0000-00032591-3386

2 Professora Adjunta Doutora da Universidade Estadual de Mato Grosso do Sul-UEMS, atua no curso de Licenciatura em Pedagogia na Unidade Maracaju/Ms. Doutora em Educação (2018) e Mestre em Educação (2013) pelo Programa de Pós-graduação em Educação- PPGE da Universidade Estadual Paulista Júlio de Mesquita Filho-UNESP/FCT, Câmpus de Presidente Prudente, na linha de pesquisa Infância e Juventude. Especialista em Educação Infantil (2010) pela UNESP/FCT. Graduada em Pedagogia (2006).Possui,também, Habilitação no Magistério para Educação Infantil (2007) pela UNESP/FCT . Graduada em Letras (2004) pela Universidade do Oeste Paulista-UNOESTE. Habilitada no Magistério em Nível Médio-CEFAM (2002). Atuou como professora de Educação Infantil na Rede Privada de Ensino-Colégio Anglo Prudentino (2003-2008) e, também, na Prefeitura Municipal de Presidente Prudente (2009-2011). Atuou como vice-diretora de escola pela Prefeitura Municipal de Pirapozinho (2009) ; como professora titular de cargo efetivo, PEB I, pelo Governo do Estado de São Paulo (2005-2015). Atuou como Professora Coordenadora de Apoio à Gestão PedagógicaPCAGP (1ㅇs sem de 2014) pelo Governo do Estado de São Paulo. Bolsista CAPES (Doutorado 20 sem 2014-2015). Atuou como Diretora de Escola na Rede Municipal de Presidente Prudente, de 2016 -2019. Tem experiência na área de Educação e atua nas áreas: Educação Infantil, Formação de professores para Educação Infantil, Gestão Escolar de instituições de Educação Infantil, saberes profissionais e abordagem autobiográfica em pesquisas educacionais. E-mail: hellen.santos@uems.br ORCID: https://orcid.org/0000-0003-3919-2786
}

Revista Devir Educação, Lavras-MG. Edição Especial, p.269-286, Set./2021. 
elas o de manter o vínculo com os alunos à distância, principalmente quando muitas destas crianças estão em situação de vulnerabilidade.

Palavras- chave: Pandemia covid; Docência; Mal-estar/bem-estar docente.

Summary: This study aims to analyze the perception and feelings of well-being and malaise of teachers, about remote education in times of pandemic. authors, such as Esteve (1999), Nóvoa (2009), Santos (2020), Saviani and Galvão (2021), Brooks (2021) and others, helped in the theoretical support to understand the complex work of teaching. Data collection took place through an online questionnaire by google forms for all teachers of basic education in the municipality of Maracaju - MS. Without a doubt, the teacher was one of the professions with the most discomfort factors, but it was also the profession that most reinvented itself during the pandemic, overcoming several difficulties, among them the one of maintaining the link with the students at a distance, especially when many of these children are in a vulnerable situation.

Keywords: Covid pandemic. Teaching. Teacher malaise / well-being.

Resumen: El presente estudio tiene como objetivo analizar la percepción y los sentimientos de bienestar y malestar de los docentes, sobre la educación a distancia en tiempos de pandemia. autores, como Esteve (1999), Nóvoa (2009), Santos (2020), Saviani y Galvão (2021), Brooks (2021) y otros, ayudaron en el sustento teórico para comprender el complejo trabajo de la docencia. La recolección de datos se realizó a través de un cuestionario en línea mediante formularios de google para todos los docentes de educación básica del municipio de Maracaju - MS. Sin duda, el docente fue una de las profesiones con más factores de malestar, pero también fue la profesión que más se reinventó durante la pandemia, superando varias dificultades, entre ellas la de mantener el vínculo con los estudiantes a distancia, especialmente cuando muchos de estos niños se encuentran en una situación vulnerable.

Palabras clave: pandemia de Covid. Enseñando. Malestar / bienestar docente.

\section{Introdução}

Há mais de um ano de pandemia, os efeitos devastadores na educação brasileiras já veem sendo sentidos em todas as etapas da educação, uma das mais perversas implicações geradas pelo ensino remoto, é o adoecimento dos professores dada a intensificação do trabalho causando sobrecarga física e emocional, em que as percepções dos docentes apontam para o mal estar docente em tempos de ensino remoto durante a pandemia.

É de domínio público a notícia de que em 11 de março de 2020 a OMS declarou a disseminação comunitária da COVID-19 em todos os continentes caracterizando-a como 
pandemia. Neste sentido, três ações básicas compuseram as principais ações para interrompêla: isolamento e tratamento dos casos identificados, testes massivos e distanciamento social.

Diante disso, Estados e Municípios decretaram instrumentos legais e normativos para o enfrentamento da emergência de saúde pública, estando, entre elas, a suspensão das atividades escolares. Em decorrência deste cenário, os Conselhos Estaduais de Educação de diversos estados e vários Conselhos Municipais de Educação emitiram resoluções e pareceres orientativos para as instituições de ensino pertencentes aos seus respectivos sistemas sobre a reorganização do calendário escolar e uso de atividades não presenciais.

A partir desta última recomendação, as escolas foram fechadas e as aulas presencias começaram a ser suspensas substituídas por atividades remotas no âmbito da educação infantil e anos iniciais nos municípios e estados brasileiros. O estado de Mato Grosso do Sul, adotou as medidas editadas pelo $\mathrm{CEE}^{3}$, e consequentemente o município de Maracaju, cidade localizada a 157,4 km da capital, Campo Grande, traçou estratégias para continuidade das aulas, durante o período de isolamento social, em consonância com esta normatização.

[...] em caráter excepcional, especificamente, para o ano letivo afetado pelas medidas de mitigação das dificuldades decorrentes da situação de emergência de saúde pública de que tratam as normas citadas, que: - as instituições de ensino, no exercício da autonomia e responsabilidade da condução dos seus respectivos projetos pedagógicos, poderão adotar estratégias que melhor se adequem à sua realidade, considerando as normas vigentes. As instituições de ensino ficam dispensadas da obrigatoriedade de observância ao mínimo de dias letivos de efetivo trabalho escolar/acadêmico, nos termos do disposto na Lei n. ${ }^{\circ}$ 9.394, de 20 de dezembro de 1996, inciso I do caput e no $\S 1^{\circ}$ do art. 24 e no inciso II do caput do art. 31, desde que cumprida a carga horária mínima anual estabelecida nos referidos dispositivos, no caso da educação básica, e nos termos do disposto no caput e no $\S 3^{\circ}$ do art. 47 da Lei n. ${ }^{\circ}$ 9.394, no caso da educação superior; - as instituições de ensino públicas e privadas poderão, se for o caso, optar por suspender as aulas, reorganizando seus Calendários Escolares, estabelecendo formas de reposição de dias letivos ou antecipação de férias e ou fazendo uso de regime especial de aulas não presenciais, mantendo o calendário já estabelecido, desde que assegurem o mínimo da carga horária obrigatória, estabelecida em Lei, e em normas próprias, podendo, inclusive, extrapolar o calendário civil de 2020 (CEE, 2020, p.87).

Estes acontecimentos e normatizações demostraram a fragilidade do sistema escolar brasileiro, em que uma solução única, claramente não foi possível para dar continuidade à

\footnotetext{
${ }^{3} \mathrm{O}$ CEE descreveu que as formas de organização e de registros de acompanhamento do desempenho do aluno; devem ser respeitadas as especificidades da educação infantil e dos anos iniciais do ensino fundamental, nos processos de aprendizagem e desenvolvimento, bem como nas práticas pedagógicas em seus diferentes contextos sociais; - devem ser respeitadas as especificidades das modalidades da educação básica, disponibilizando diferentes procedimentos metodológicos, recursos e avaliação, considerando as condições individuais, quanto aos aspectos cognitivos, afetivos, sociais e culturais dos alunos.
} 
aprendizagem de conteúdo escolar, evidenciando as desigualdades educacionais entre redes públicas e privadas de nosso país. Além disso, pairou a dúvida de que formatos de atividades as redes de ensino deveriam recorrer neste período para atender a diversidade socioeconômica e de acesso aos estudantes, sem necessariamente serem aquelas mediadas por dispositivos tecnológicos e ou online, dada a vulnerabilidade de grande parte dos estudantes das redes públicas de ensino.

Saviani e Galvão (2021) destacam que a pandemia do novo coronavírus provocou a necessidade de fechamento das escolas, o que levou ao "ensino" "remoto em substituição às aulas presenciais, por isso a expressão: ensino remoto passou a ser usada como alternativa à educação a distância (EAD). "[...] a EAD já tem existência estabelecida, coexistindo com a educação presencial como uma modalidade distinta, oferecida regularmente" (SAVIANI; GALVÃO, 2021, p. 38).

Segundo Garcia (2020) ensino remoto significa um conjunto de atividades de ensinoaprendizagem diversificadas que podem incluir desde videoaulas ou ensino online, como também atividades impressas enviadas aos alunos, leitura de livros". Destarte, o conceito de ensino remoto vem do termo "remoto" que significa distante no espaço e se refere a um distanciamento geográfico, tanto os professores como os estudantes estão impedidos, por leis, de frequentarem as escolas e ou instituições para não disseminar o covid-19, considerado emergencial. E de um dia para outro os professores tiveram que repensar todo o planejamento pedagógico e ajustar atividades mediadas pelo uso da internet, celulares e outros afins, tentando minimizar os impactos da transição de ensino presencial.

Compreendemos que o ensino remoto pressupõe o distanciamento geográfico de professores e alunos e que foi necessário adotar, de forma temporária, nos diferentes níveis de ensino do mundo inteiro para que as atividades escolares não fossem interrompidas. No entanto, é certo que sucesso deste tipo de ensino depende da atuação do professor. Neste sentido, questionamos: diante da adoção repentina de inúmeras estratégias, a exigência de "novas" práticas pedagógicas, aprendizagem de conhecimentos e habilidades necessários para o ensino remoto: a percepção é de bem-estar e ou mal-estar docente? Quais são as condições

\footnotetext{
4 "Ensino", pois os autores compreendem que essa estratégia não se configura ensinar, por razões pedagógicas.
} 
de trabalho que dispõe para o ensino remoto? O ensino remoto se apresenta como mais um dos fatores de mal-estar, presente no trabalho docente?

Com o objetivo de analisar aspectos do bem-estar e mal estar docente, traçamos uma pesquisa de cunho qualitativo, porque segundo Ludke e André (1986, p.13) "[...]envolve a obtenção de dados descritivos, obtidos no contato direto do pesquisador com a situação estudada, enfatiza mais o processo do que o produto e se preocupa em retratar a perspectiva dos participantes" (LUDKE; ANDRÉ, 1986, p. 13). Além disso, o conhecimento é processo socialmente construído pelos sujeitos nas suas interações cotidianas enquanto atuam na realidade, transformando-a e sendo por ela transformados.

A coleta de $\operatorname{dados}^{5}$ se deu por meio de questionário, que foram disponibilizados via on-line para todos os professores da rede pública municipal da educação de Maracaju -MS com o apoio da Secretaria de Educação da localidade (SEME), que conta com 6 Centros Integrados de Educação Infantil e 11 Escolas Municipais de Ensino Fundamental e também com o apoio das coordenações das 4 escolas privadas, bem como para os professores da rede privada, da Educação Infantil, e do Ensino Fundamental de Maracaju-MS.

O questionário foi elaborado com 13 questões de múltipla escolha sobre sexo, faixa etária, estado civil, nível e rede de atuação, para conhecermos o perfil dos professores e questões como saúde, percepção sobre o ensino remoto e apoio que consideram importante neste momento atual, para auxiliar no bem-estar docente. Nas seções que seguem apresentamos as discussões e análises.

\section{O trabalho docente em tempos de pandemia: novos caminhos a trilhar?}

Os professores se sentirem desprestigiados, fragilizados e sobrecarregados não aconteceu somente na pandemia de 2020, para vários autores: (Nóvoa, 2009; Marcelo Garcia, 2010; Tardif, 2002; Jesus, 2007), as últimas décadas, na sociedade contemporânea industrializada, assistimos uma desvalorização e aumento nas exigências sociais sobre o papel do professor.

\footnotetext{
${ }^{5}$ A pesquisa passou por validação do comitê de ética, devidamente cadastrado na plataforma Brasil.
} 
Isso se deu por conta de vários fatores, entre eles: a passagem de um ensino da elite para um ensino de massas; Alargamento da escolarização obrigatória (a escola deixou de ser compreendida como uma ponte, uma garantia para a ascensão social e econômica e passou a ser vista como uma imposição, um dever, acarretando, assim, desinteresse e indisciplina por parte dos alunos); muitos professores ingressaram na carreira por falta de opção e não por vocação, de forma transitória; No plano de valores sociais, nesta sociedade economicista, as profissões mal pagas, como é o caso da docência, são desvalorizadas (a valorização social, o status social está ligado a valorização salarial); O desenvolvimento dos meios de comunicação passou a permitir o acesso mais fácil e atraente aos jovens, contribuindo para a desvalorização do transmissor do conhecimento que era o papel do professor, exigindo assim, novos conhecimentos e procedimentos nas práticas pedagógicas desenvolvidas em sala de aula.

E Connell (2010, p.173), explicita que o trabalho do professor passa por inúmeras complexidades: “[...] o trabalho em sala de aula envolve um fluxo de emoções tanto da parte dos professores como dos alunos, que variam desde simpatias e antipatias até entusiasmo, ansiedade, tedio, alegria, medo e esperança" e os professores têm que lidar com todas essas emoções e transforma-las em aprendizado para os alunos e para ele próprio poder sobreviver.

Assim, o papel do professor vai muito além de transmitir um conjunto de informações e fatos aos alunos. "[...] eles necessariamente interpretam o mundo para - e com - seus alunos" (CONNELL, 2010, p.177) e para que esse profissional possa interpretar o mundo para outros é necessário bem mais do que um conjunto de habilidades: é necessário o conhecimento de como essa interpretação ocorre, em que campo cultural ocorre e quais outras possibilidades de interpretações existem - este é o conceito de trabalho intelectual, nos diz Connell (2010), os professores devem ser considerados "como um grupo de trabalhadores intelectuais" que tem um conceito bem mais amplo do que trabalhadores do conhecimento, porque requer um conhecimento profundo da cultura e a prática de análise crítica, que são da alçada de sujeitos intelectuais.

E para além dessa complexidade, em sala de aula o trabalho docente não se resume apenas em "dar aulas", planejar, elaborar avaliações e correções, é bem mais que isso e alguns exemplos para além da sala de aula são: participar da elaboração da proposta pedagógica e do 
currículo, participar de recreios orientados, relacionar-se com as famílias de seus alunos, como explicita Gama e Terrazzan (2012, p.14):

[...] o trabalho dos professores abarca outras ações para além do trabalho didático, como por exemplo: elaborar a proposta pedagógica da escola, elaborar o currículo escolar, participar de recreios orientados, fazer contato com os pais e se envolver com a comunidade, etc.

Concordamos com Esteve (1999), quando afirma que o processo ensino aprendizagem não acontece com a qualidade desejada, não porque o professor não esteja motivado ou não saiba como fazer, mas porque não há condições que permitam implementar essa qualidade, portanto "o professor é uma pessoa condenada a desempenhar mal o seu trabalho". E em tempos de pandemia, quando "o advento da doença Covid - 19 e do isolamento social redesenhou a forma de ensinar e aprender, afetando atividades na educação básica e superior por meio da suspensão de aulas presenciais" (AMORIN; COSTA, 2020, p.86), quais são as condições dos professores para trabalhar de forma remota? Estão motivados? Sabe como fazer? Ou essa é mais uma das complexidades desse trabalho? Desenvolvem mais fatores de bem-estar e ou de mal-estar docente?

\section{A quarentena e as aulas remotas emergenciais}

Para Brooks et al. (2020), a palavra "quarentena" foi usada pela primeira vez na Itália, em 1127, e posteriormente no surto da SARS na China, em 2003, e do vírus Ebola na África, em 2014. Ela se refere à “[...] separação e restrição do movimento de pessoas que foram potencialmente expostas a uma doença contagiosa para verificar se elas ficam mal, reduzindo assim o risco de infectar outras pessoas" (BROOKS et al., 2020, p. 912).

O conceito de aulas remotas vem do termo "remoto" que significa distante no espaço e se refere a um distanciamento geográfico. Tanto os professores como os estudantes estão impedidos, por leis, de frequentarem as escolas e ou instituições para não disseminar o covid19, considerado emergencial. E de um dia para outro os professores tiveram que repensar todo o planejamento pedagógico e ajustar atividades mediadas pelo uso da internet, celulares e outros afins, tentando minimizar os impactos da transição de ensino presencial.

Compreendemos o Ensino Remoto Emergencial (ERE) como uma modalidade de ensino que pressupõe o distanciamento geográfico de professores e alunos e que foi 


\section{OD DEVIR EDUCAÇÃO \\ ISSN: 2526-849X}

necessário adotar, de forma temporária, nos diferentes níveis de ensino do mundo inteiro para que as atividades escolares não fossem interrompidas.

Boaventura de Sousa Santos (2020) no livro "a cruel pedagogia do vírus" comenta que estamos vivendo a "normalidade da exceção". Precisamos nos isolar para sobreviver. Em tempo de pandemia e afastamento social, sem mais nem menos e que aconteceu da noite para o dia; ou de um dia para outro, o lar passou a ser para quase todos os professores do país, senão do mundo, o lugar de trabalho.

Isso certamente afetou, em graus diferenciados, a rotina de vida e de relacionamento de cada um desses professores, "colocando a prova a sua capacidade de regular as emoções" (GONDIM, BORGES, 2020, p.1), sem que estivessem preparados para isso. Os professores nem sequer havia pensado nesta possibilidade e precisam de muito esforço para se adaptarem a nova realidade, portanto provavelmente vivenciam um turbilhão de sentimentos, incluindo a angustia e a ansiedade, a essa nova condição, ainda provisória de viver. Afinal o trabalho é a principal atividade na interação com o mundo e segundo Gondim e Borges (2020, p. 3):

[...]se aprendi ao longo de minha vida que o trabalho tem uma importante função de sociabilidade, isso é o que acabou dando sentido ao meu trabalho até então. Quando me vejo em afastamento presencial e sinto distanciamento de meus colegas, isso exige criar novas formas de sociabilidade para preservar este sentido do trabalho.

Para que isso aconteça, segundo essas autoras, é necessário um auto regulação que envolva tanto os pensamentos, as emoções e as ações, contribuindo assim para o bem-estar tanto físico quanto mental o que não é uma tarefa fácil, porque nós estamos mais preparados para reagir de forma impulsiva às perturbações do que para tolerar sentimentos que nos incomoda, o que leva ao estresse.

Um grupo de doutores pesquisadores na área da psicologia publicaram uma cartilha que visa à promoção da saúde e bem-estar denominada "Enfrentando o estresse em tempos de pandemia: Proposição de uma cartilha" e comentam que no contexto da epidemia do COVID19, os principais estressores têm várias causas, entre elas: a duração da quarentena, o distanciamento social, à frustração e o tédio, o acúmulo de tarefas, à falta de suprimentos, informações inadequadas e dificuldades econômicas assim como também, as relacionadas à 
própria COVID-19 incluindo o medo de contrair a doença, a preocupação com a própria saúde e de entes queridos, ao estigma da doença, entre outras.

\section{Metodologia de pesquisa}

A presente pesquisa é de natureza qualitativa. A abordagem qualitativa, segundo Ludke e André (1986, p. 13), “envolve a obtenção de dados descritivos, obtidos no contato direto do pesquisador com a situação estudada, enfatiza mais o processo do que o produto e se preocupa em retratar a perspectiva dos participantes".

A pesquisa de abordagem qualitativa, "concebe o conhecimento como um processo socialmente construído pelos sujeitos nas suas interações cotidianas enquanto atuam na realidade, transformando-a e sendo por ela transformados" (ANDRÉ, 2013, p. 97). A centralidade da pesquisa qualitativa está nas motivações, nas interações, nas vivências, na linguagem, nas experiências cotidianas, bem como nas expectativas dos sujeitos investigados, que é a centralidade desta pesquisa.

A coleta de dados se deu por meio de questionário on-line - google forms, que foram disponibilizados via on-line - para todos os professores da rede pública municipal da educação de Maracaju -MS com o apoio da Secretaria de Educação da localidade (SEME), que conta com 6 Centros Integrados de Educação Infantil e 11 Escolas Municipais de Ensino Fundamental e também com o apoio das coordenações das 3 escolas privadas, para os professores da rede privada, da Educação Infantil, Anos Iniciais e finais do Ensino Fundamental de Maracaju-MS.

O questionário foi elaborado com 13 questões de múltipla escolha sobre sexo, faixa etária, estado civil, nível e rede de atuação, para conhecermos o perfil dos professores e questões como saúde, percepção sobre as aulas remotas e apoio que consideram importante neste momento atual, para auxiliar no bem-estar docente.

\section{Resultados e discussão}

Ao analisarmos os dados coletados sobre o perfil dos professores verificamos que: 90,8\% são do sexo feminino; 47,9\% trabalham nos anos iniciais do Ensino Fundamental; 
38,7\% na Educação Infantil e 13,4\% nos anos finais do Ensino Fundamental. 37,8\% tem entre 30 a 40 anos de idade; $32,7 \%$ de 40 a 50 anos de idade; $12 \%$ de 20 a 30 anos de idade; $10,6 \%$ de 50 a 60 anos de idade, e 6,9\% mais de 50 anos de idade.

$87,6 \%$ trabalham na rede pública municipal de ensino e 11, 5\% nas escolas privadas no município e destes professores: $63,6 \%$ são concursados; $30,4 \%$ são contratados e $6 \%$ trabalham em regime de CLT.

$34,6 \%$ trabalham de 10 a 20 anos como professores; $28,1 \%$ de 5 a 10 anos; $21,2 \%$ trabalham a menos de 5 anos e 16,1\% trabalham a mais de 20 anos como professores.

Sobre os professores serem mais de $90 \%$ do sexo feminino, Boaventura Sousa Santos (2020), explica que a quarentena sempre será discriminatória, ou seja, será mais difícil para alguns grupos do que outros e o grupo de professores mulheres é um dos mais vulnerável, por se tratar de uma profissão de cuidadores, e segundo ele é "impossível para um vasto grupo de cuidadores, cuja missão é tornar possível a quarentena ao conjunto da população" (p. 15).

Ao analisar os grupos para os quais a quarentena é mais difícil, porque padecem de uma vulnerabilidade que se agrava ainda mais, Boaventura explica que são: Os trabalhadores precários, informais, ditos autónomos; Os trabalhadores da rua e ou os vendedores ambulantes; Os sem-abrigo ou populações de rua; Os moradores nas periferias pobres das cidades, favelas; Os internados em campos de internamento para refugiados, imigrantes indocumentados ou populações deslocadas internamente; Os deficientes; os idosos e as mulheres.

Mas, porque as mulheres? Segundo esse autor, porque elas são consideradas "as cuidadoras do mundo". São elas na grande maioria, que predominam nos cuidados da família e também são elas que predominam nas profissões como enfermagem, assistência social e de professor.

E os professores da educação infantil e anos iniciais, assim como os profissionais que cuidam de doentes e idosos, tem a característica do "cuidado" ainda mais marcante. Segundo Marchesi (2008, p.24) "o ensino se afasta da imparcialidade e do distanciamento pessoal da maioria das profissões e inclui, como uma de suas marcas de identidade, o cuidado da relação interpessoal, o envolvimento afetivo e o comprometimento pessoal".

O cuidado é definido por Codo (1999) como "uma relação entre dois seres humanos cuja ação de um resulta no bem-estar do outro". O trabalho de professor tem que ter uma 
atenção particularizada ao outro, que é o que diferencia entre o fazer e o não fazer sua obrigação.

\section{Sobre as aulas remotas}

Primeiro acreditamos que seja necessário compreendermos o que seja aulas remotas, no que se diferencia de Educação a distância. Foi a partir do advento da pandemia do novo coronavírus, que as escolas tiveram que ser fechadas, o que levou ao ensino remoto para substituir as aulas presenciais. "A expressão ensino remoto passou a ser usada como alternativa a educação a distância (EAD). Isso, porque a EAD já tem existência estabelecida, coexistindo com a educação presencial como uma modalidade distinta, oferecida regularmente" (SAVIANI; GALVÃO, 2021, p. 38).

Portanto, diferente do EAD, o ensino remoto é compreendido como um substituto para a educação presencial de forma excepcional neste período de pandemia, que se encontra interditada, e a maioria dos professores, sem nenhum preparo prévio, tiveram, de uma hora para outra que utilizar plataformas e dispositivos de comunicação remota, gerando sentimentos de incapacidade, frustração e desgaste nos professores, suscitando empobrecimento do trabalho pedagógico apesar do excesso de atividades, por conta do pouco retorno das atividades realizadas pelos alunos.

98,2\% dos professores entrevistados, responderam que estão trabalhando de forma remota.

As formas como eles trabalham, 70,5\% responderam que estão ministrando aula por meio de atividades enviadas para o celular dos pais dos alunos; 63,6\% responderam que as atividades são impressas e os alunos, pais ou responsáveis vem até a escola para recolher e ou entregar. 32\% respondeu que ministra as aulas pelo google meet e ou similares; e 11,1\% responderam outros sem especificar quais sejam, segundo Saviani e Galvão (2020, p.38):

Determinadas condições primarias precisariam ser preenchidas para colocar em pratica o "ensino" remoto, tais como o acesso ao ambiente virtual propiciado por equipamentos adequados (e não apenas celulares); acesso a internet de qualidade; que todos estejam devidamente familiarizados com as tecnologias e, no caso de docentes, também preparados para o uso pedagógico de ferramentas virtuais.

Porém, de maneira geral, o que existe, principalmente nas escolas públicas, é a ausência de condições mínimas de ensino aprendizagem tanto para a grande maioria dos alunos e também para uma grande parcela de professores, que, acabaram tendo que arcar com 
os custos e prejuízos de saúde física e mental decorrentes da intensificação e precarização do trabalho.

\begin{abstract}
Educadoras/es, em sua maioria, tiveram de uma hora para outra utilizar plataformas e dispositivos de comunicação remota sem preparo prévio. A pressão dos sistemas de ensino para o trabalho remoto tende a gerar um empobrecimento do trabalho pedagógico tendo como consequência, a prevalência do conteudismo, o excesso de atividades, o desgaste e frustração pelo pouco retorno dessas atividades, a sensação de impotência das famílias e o sentimento de incapacidade das/os educadoras/es (NUNES, et.al, 2021, p.841).
\end{abstract}

Os docentes estão abarrotados de trabalhos para corrigir, mensagens de e-mails e aplicativos, fóruns de ambientes virtuais e outros para dar conta, tudo isso intensificando o adoecimento docente. Porque além da pressão e vigilância imposta, o uso constante das tecnologias, com as quais nem todos estão familiarizados, amplia as possibilidades de adoecimento físico e mental. "A elevação da carga de trabalho se dá, ainda, em condições subjetivas desfavoráveis, uma vez que muitas e muitos docentes tem que lidar com o tele trabalho em meio a afazeres domésticos e demandas familiares (SAVIANI, GALVÃO, 2020, p. 12).

\title{
Percepção sobre as aulas remotas e o ensino aprendizagem
}

Sobre a percepção em relação as aulas remotas e a aprendizagem dos alunos, 60,8\% responderam que são pouco produtivas; $36,4 \%$ responderam que as aulas são produtivas. Apenas $2,3 \%$ acreditam que as aulas remotas não são nada produtivas e ninguém respondeu muito produtiva.

$41,9 \%$ responderam que ao migrar para as aulas remotas se sentiram inseguros, mas confiante que conseguiriam; 33,6\% motivados com a oportunidade de novas aprendizagens; $19,8 \%$ despreparados para enfrentar o desafio.

São vários os desafios para o professor trabalhar em casa no sistema de home-office. Um deles está nas condições que dispõe para isso, como por exemplo a necessidade de espaço próprio para o trabalho separado das atividades e do funcionamento geral do lar, porém nem todos os professores dispõe desse espaço.

Sabemos que a maioria dos professores moram em espaços pequenos, com familiares, as vezes crianças e idosos, e que nem sempre consegue espaços ou cômodos para separar 
trabalho do funcionamento geral do lar e o primeiro desafio talvez seja esse: "precisamos encontrar alternativas para demarcar melhor o espaço e o tempo dedicado ao trabalho, aos afazeres domésticos e à convivência familiar" (GONDIM, BORGES, 2020, p. 4).

Amorim e Costa (2020, p.87)), explicitam que "o surgimento do novo coronavírus modificou a rotina de professores e estudantes de modo que desafios surgiram: a qualidade do trabalho dos professores pode ser prejudicada pela divisão da atenção com rotinas caseiras; falta de equidade na acessibilidade às Tecnologias Digitais (TD)" entre outras tantas dificuldades.

Dos professores questionados sobre as modificações na rotina do seu dia a dia, 39,2 $\%$ responderam que mudou totalmente; $36,4 \%$ que precisou mudar muito os hábitos, Boaventura Souza Santos, comenta que em função do confinamento familiar, e portanto de as famílias terem passado bem mais tempo em casa poderíamos acreditar que haveria mais braços para distribuir as tarefas mas que por conta do machismo que impera na maioria dos lares, "[...] Com as crianças e outros familiares em casa durante 24 horas, o stress será maior e certamente recairá mais nas mulheres"(SANTOS, 2020, p.16).

Principalmente para as mulheres professoras, o trabalho triplicou, elas têm que tomar conta das tarefas da casa, da escola e dos filhos. Santos (2020), ainda alerta para a necessidade de se levar em conta o número de divórcios e violências contra as mulheres que aumentaram de forma assustadora. Apenas $1,8 \%$ responderam que sua rotina continua a mesma, talvez, essa resposta seja dos professores que estão em licença desde o início do ano de 2020.

\section{Aulas remotas e as escolas privadas $\mathbf{X}$ escola pública}

Os $32 \%$ que responderam que ministram as aulas pelo google meet e ou similares; são professores das escolas privadas. Essas escolas rapidamente buscaram se adequar utilizando as tecnologias digitais e por isso repensaram as metodologias de ensino voltados para plataformas online. Porém esses recursos e instrumentos não foram oferecidos para as escolas públicas e para centenas de estudantes.

[...] num mundo movido pelas tecnologias digitais, ninguém pode ser privado de usufruir deste bem tão importante, sob o risco de perder diversas oportunidades e de ter seu campo de possibilidades reduzido, razão pela qual há que se ter uma política de acesso à internet democratizada em todo o mundo e, especialmente, no Brasil.( SOUZA; MELO; SILVA SOUZA, 2011, p.7)

Revista Devir Educação, Lavras-MG. Edição Especial, p.269-286, Set./2021. 


\title{
OO DEVIR EDUCAÇÃO \\ ISSN: 2526-849X
}

O ensino remoto emergencial deu continuidade aos debates sobre o "fosso" da desigualdade existente entre a esfera pública e privada no Brasil e acendeu as discussões sobre a implantação do Ensino à Distância e o papel da educação pública.

\begin{abstract}
Nesse viés, a exclusão digital ocorre porque as famílias com baixo poder aquisitivo não têm condições de comprar computador, tablet ou celular para os seus filhos , nem de pacote de internet suficiente para que eles estudem online. Assim, no contexto escolar, os alunos das classes mais desfavorecidas da sociedade não terão as mesmas condições de estudo que alunos oriundos das classes média e alta, o que contribuirá para o aumento da exclusão social mais ampla ( SOUZA; MELO; SILVA SOUZA, 2011, p.6)
\end{abstract}

Além da falta de acesso e recursos para acessar as plataformas digitais, os professores terem que ir até a escola para entregar as atividades e os pais e ou estudantes para buscar as atividades também é uma "exposição ao risco" de contaminação. A pandemia veio nos ressaltar questões que a escola pública x privada já traçam dá décadas.

Nóvoa e Alvim (2020) explicitam que as medidas adotadas na pandemia não traçam o fim da escola, mas uma metamorfose que aponta para possibilidades de renovação. Para eles, devemos reconhecer a capilaridade educacional, ou seja, os processos educativos formais e informais; transformar a estrutura organizacional da escola e suas metodologias de ensino; reforçar a educação como um bem público e comum; e enfatizar a importância dos docentes na construção de novos ambientes educacionais.

\section{Sobre a saúde do professor}

Estudos mostram que, na pandemia, vivencia-se uma alta carga negativa de experiências e de emoções, (SARAIVA et al., 2020, PEREIRA et al., 2020). Soma-se a esse fato o afastamento familiar e social, as incertezas quanto ao futuro, o tédio, medo, informações confusas ou mentirosas, chamadas de fakenews.

Brooks et al., (2020), também concordam que, no contexto da epidemia do COVID19, alguns dos principais estressores estão relacionados à duração da quarentena, ao distanciamento social, à frustração e ao tédio, ao acúmulo de tarefas, entre outras incluindo o medo de contrair a doença, a preocupação com a própria saúde e de entes queridos, ao estigma da doença.

Revista Devir Educação, Lavras-MG. Edição Especial, p.269-286, Set./2021. 
Dos professores investigados, $37,8 \%$ disseram estar muito preocupado com a sua saúde; $37 \%$ responderam que estavam um pouco preocupados; $19,8 \%$ disseram estar muito preocupados e 4,6\% responderam que não estavam preocupados.

A docência é uma das ocupações mais estressantes, por conta das circunstancias atuais que se mostram desafiadoras, assim, não é apenas a saúde física e mental, mas também o desempenho desses profissionais, sofrem prejuízos, nesse sentido, Baptista, et al, (2019) explicitam que a chance de professores desenvolverem estresse, depressão, ansiedade é duas vezes maior, comparado com as demais profissões. No Brasil, estas ocupam o segundo lugar na categoria das doenças ocupacionais.

\section{Considerações finais}

A pandemia evidenciou de forma escancarada as desigualdades existentes em nosso país, na educação não foi diferente, o "fosso" da desigualdade educacional foi acentuado ainda mais. Teremos pela frente enormes desafios para serem superados, mas também precisamos olhar para frente e aproveitar os aprendizados que colhemos neste difícil caminhar. Sem sombra de dúvida o professor foi uma das profissões que mais se reinventou durante a pandemia. Superamos várias dificuldades, entre elas o de manter o vínculo com os alunos à distância, principalmente quando muitas destas crianças estão em situação de vulnerabilidade. Mas os professores encararam os desafios, inclusive o uso da tecnologia, e se reinventaram. Mais do que nunca, ficou claro que esta é uma profissão indispensável na construção de um futuro melhor.

Ao perceberem que nem tudo estava ao seu alcance, como acesso à internet e aparelhos eletrônicos para todos os alunos, ou participação da família no processo de aprendizagem e vínculo com a escola, os professores se sentiram ansiosos e sobrecarregados, mas não desistiram, apesar de todas as mudanças na sua rotina, seguiram em frente.

Preocupar-se com o bem-estar docente nada mais é, do que apoiar a construção de uma Educação de qualidade para todo o país, um tema que sempre permeou o debate da Educação, mas que ganhou ainda mais importância com tantos desafios impostos pela pandemia, porém, a mudança só pode ocorrer com políticas públicas que incentivem e 
possibilitem os recursos tecnológicos, os materiais, os espaços necessários para atender a todos com qualidade.

Também é imperativo compreendermos que em toda crise também há oportunidades, e esta pandemia nos mostrou que há espaço para uma maior valorização da profissão de professor, considerado um dos mais importantes fatores para o bem-estar docente. Enfim, é necessário que a sociedade olhe para esses profissionais de um lugar mais humano, e compreenda que o bem-estar docente é imprescindível por ser considerado um elemento primordial para que a qualidade da educação brasileira realmente se efetive.

\section{Referências}

ANDRÉ, Marli. O que é Um Estudo de Caso Qualitativo em Educação? Revista da FAEEBA - Educação e Contemporaneidade, Salvador, v. 22, n. 40, p. 95-103, jul./dez. 2013

AMORIM, Douglas Carvalho.; COSTA, Jane Araújo Costa. Impactos da pandemia Covid-19 no processo formativo de professores de Biologia de um mestrado profissional: desafios em tempos de quarentena. Revista Devir Educação, Lavras, vol.2, n.4, p.80-103, jul./dez., 2020

BAPTISTA, Makilim Nunes., et.al. Burnout, estresse, depressão e suporte laboral em professores universitários. Revista Psicologia Organizações e Trabalho,19(1), 564-570, 2019.

BROOKS, Samantha. Et.al. K.; The Psychological Impact of Quarantine and How to Reduce It: Rapid Review of the Evidence. The Lancet, [S. l.], v. 395, n. 10227, p. 912-920, 2020. DOI: http://dx.doi. org/10.1016/S0140-6736(20)30460-8. Disponível em: https://www.thelancet.com/action/showPdf?pii=S0140-6736\%2820\%2930460-8

Acesso em: 22 maio 2020.

CODO, Wanderley. Educação: carinho e trabalho. Petrópolis: Vozes, 1999.

CONNELL, Raewyn. Bons professores em um terreno perigoso: rumo a uma nova visão de qualidade e do profissionalismo. Educação e pesquisa, são Paulo, v.36, n. especial, p.165184, 2010.

ESTEVE, José Manuel Zaragoza. O mal-estar docente: a sala de aula e a saúde dos professores. Tradução de Durley de Carvalho Cavicchia, Bauru/SP: EDUSC, 1999.

GAMA, Maria Eliza Rosa.; TERRAZZAN, Eduardo Adolfo. o trabalho docente: expectativas e interesses da pesquisa educacional nas últimas décadas no Brasil. Anais da 35ạ Reunião Nacional da ANPED, 2012. disponível em http://www.anped.org.br/sites/default/files/gt08-2393 int.pdf. 
GARCIA, Luís Manuel Mendes. Associação Nacional de Educação Católica no Brasil, https://anec.org.br/noticias/desafios-para-educacao-em-tempos-de-pandemia/ acesso em: 20/05/2020.

GONDIM, Sonia.; BORGES, Lívia de Oliveira. Significados e Sentidos do Trabalho do Home-Office: Desafios para a Regulação Emocional. In: Orientações técnicas para o trabalho de psicólogas e psicólogos no contexto da crise COVID-19. 2020. https://www.sbpot.org.br/central-de-conteudo-covid19/wpcontent/uploads/2020/04/SBPOT_TEMATICA_5_Gondim_Borges.pdf.

JESUS, Saul Neves de. Professores sem stress: realização profissional e bem-estar docente. Porto Alegre: Mediação. 2007.

LÜDKE, Menga.; ANDRÉ, Marli. Pesquisa em educação: abordagens qualitativas. São Paulo: EPU, 1986.

MARCELO GARCIA, Carlos. O professor iniciante, a prática pedagógica e o sentido da experiência. Revista Brasileira de Pesquisa sobre Formação Docente, vol. 2, no 3, ago/dez, p. 11-49, 2010.

MARCHESI, Alvaro. O bem-estar dos professores: competências, emoções e valores. Porto Alegre: Artmed, 2008.

NUNES, Liliane dos Guimarães Alvim; et al. Psicologia escolar em tempo de pandemia: dilemas, incertezas e perspectivas de atuação. In: NEGREIROS, Fauston.; FERREIRA, .Breno de Oliveira (Orgs.). Onde está a psicologia escolar no meio da pandemia? São Paulo: Pimenta Cultural, 2021. https://www.ifpi.edu.br/noticias/eBook_PsicologiaEscolar.pdf. Acesso em:03/04/2021.

NÓVOA, Antonio Sampaio da. Professores: Imagens do Futuro Presente. Educa. Lisboa, 2009.

NÓVOA, Antonio Sampaio da; ALVIM, Yara. Nothing is new, but everything has changed: A viewpoint on the future school. Prospects 49, 2020, p. 35-41. Disponível em: https://rdcu.be/cfn6V. Acesso em: dez. 2020.

PEREIRA, Mara Dantas, et al. A pandemia de COVID-19, o isolamento social, consequências na saúde mental e estratégias de enfrentamento: Uma revisão integrativa. Research Society and Development, 9(7), e652974548, 2020.

SANTOS, Boaventura Souza. A cruel pedagogia do vírus. Coimbra: Editor Edições Almedina, Abril, 2020. http://www.abennacional.org.br/site/wpcontent/uploads/2020/04/Livro_Boaventura.pdf acesso em: 14/11/2020. 


\section{OD DEVIR EDUCAÇÃO \\ ISSN: 2526-849X}

SARAIVA, Illyushin Zaak, et. al. Impactos das Políticas de Quarentena da Pandemia Covid19, Sars-Cov-2, sobre a CT\&I Brasileira: prospectando cenários pós-crise epidêmica. Cadernos de Prospecção, 13(2 COVID-19), 378, 2020.

SAVIANI, Dermeval; GALVÃO, Ana Carolina. Educação na pandemia: a falácia do "ensino" remoto. Pandemia da COVID-19: trabalho e saúde docente. UNIVERSIDADE e SOCIEDADE \#67, ANDES-SN n Ano XXXI - janeiro de 2021.

SOUZA, Jose Batista de; MELO, Daniele Santana de; SILVA SOUZA, Suely Cristina. Possibilidades e desafios no trabalho docente em tempos de pandemia: uma experiência significativa na Faculdade do Nordeste da Bahia. Olhar de professor, Ponta Grossa, v. 24,p. 1-25, e-15952.041,2021.Disponível em https://revistas2.uepg.br/index.php/olhardeprofessor acesso em: 22 de maio de 2021.

TARDIF, Maurice. Saberes docentes e formação profissional. Petrópolis: Vozes, 2002.

Recebido em: 06/07/21

Aprovado em: 01/09/21

Revista Devir Educação, Lavras-MG. Edição Especial, p.269-286, Set./2021. 